\title{
Color Value, Free Amino Acid Content, and Antioxidant Potential of Seasoning Prepared with Hot Pepper Seeds
}

\author{
Kil Su Jang1', Chan Yong Kim¹, Oh Hun Kwon¹, Jung-Bae Kwon', \\ Sanjeev Kumar Dhungana², Yong-Sung Park², Hyeon-Min Do², \\ Hye-Ryun Kim³, Jin-Hwan Son ${ }^{4}$, Il-doo Kim ${ }^{5}$
}

\author{
${ }^{1}$ Yeongyang Pepper Research Institute, Gyeongsangbuk-Do Agri. R\&E Services, Yeongyangchangsu-ro 36531, \\ Korea \\ ${ }^{2}$ School of Applied Biosciences, Kyungpook National University, Daegu 41566, Korea \\ ${ }^{3}$ Cheonnyeonmiin Co. Ltd., Gyeongju-si 38180, Korea \\ ${ }^{4}$ Chachanson, 165-1, Yeonil-ro, Saengji-ri, Yeonil-eup, Nam-gu, Pohang-si, Gyeongsangbuk-do 37847, Korea \\ ${ }^{5}$ International Institute of Agricultural Research and Development, Kyungpook National University, Daegu 41566, \\ Korea
}

\begin{abstract}
Spices and herbs also known as seasonings are increasingly cherished not only for their culinary properties but also for their potential health benefits. Objective of the present study was to evaluate the physicochemical properties of seasonings containing different concentrations of pepper seed powder. Addition of hot pepper seed powder to the seasonings enhanced the color values and antioxidant potentials. The antioxidant activity, as 1,1-diphenyl-2-picrylhydrazyl (DPPH), of seasonings increased by up to $13.42 \%$. Total phenolics content was also increased by $75.43 \%$ with the addition of $15 \%$ pepper seed powder. Although some of the amino acid contents were found to be reduced while others were increased, results of this study suggest that addition of hot pepper seed powder to the seasonings could impart better physicochemical properties as well as enhance the antioxidant potential.
\end{abstract}

Keywords: DPPH, Culinary, Physicochemical Property, Polyphenol, Spice

\section{Introduction}

Spices and herbs also known as seasonings have been used in a variety of cultures for a long time and contribute not only flavors but also serve as colorants and preservatives. The terms seasonings are usually used together to describe parts of aromatic plants like bark, buds, flowers, leaves, fruits, bulbs, roots or seeds.

Today, seasonings are increasingly cherished not only for their culinary properties but also for their potential health benefits. Generally, spices are highly aromatic due to their high contents of essential oils, whereas herbs are low in essential oils and usually used to produce delicate or subtle flavors in food preparations (Chi and $\mathrm{Wu}, 2007)$. Spices are used in different forms; whole spices, ground spices, or isolates from their extract (Srinivasan et al., 2004).
They can add flavor and variety to food. Seasonings are used for flavor, medicine, color as well as a preservative, that kills harmful bacteria or prevent their growth (Ernst and Pittler, 2000). They are known to possess a variety of antioxidant properties (Zheng and Wang, 2001). Many spices and herbs have been assayed and found to possess very high antioxidant potential (Paur et al., 2011). Phenolic compounds present in the spices contribute significantly to their antioxidant capacity (Shan et al., 2005). The antioxidant activity of herbs and spices could play an important role in suppressing viral replication, inhibiting allergy and arthritis, preventing cancer and heart diseases (Aggarwal et al., 2002). Various spice-derived ingredients possess potential inhibitors of lipid peroxidation in cell and low density lipoprotein cholesterol in human (Naidu and Thippeswamy, 2002). Because of increasing health 
consciousness, consumers are found to be more interested in food formulations containing natural ingredients as compared to synthetic ones and it has motivated the food industry to evaluate the effectiveness of naturally occurring components of food for functional purposes.

The nutritional composition of hot pepper seeds showed that they could be considered as good sources of food ingredients and as new sources of edible oils (Zou et al., 2015). Hot pepper seed demonstrated significant health-promoting effects, having excellent anti-obesity activities (Jeon et al., 2010). In another study, hot pepper seeds showed strong antiproliferative activity against tumor cells (Jeon et al., 2012). As pepper seed is one of the major fruits in the world conferring health benefits due to their antioxidant activity (Kedage et al., 2007), phytosterols (Ruggieroa et al., 2013), and also contains a characteristic color value for seasonings, the present study aimed to evaluate the physicochemical changes in the seasonings by addition of various concentrations of pepper seed.

\section{Materials and Methods \\ Materials}

Hot pepper (capsicum annuum L.) cv. Longgreenmat was obtained from Yeongyang Pepper Experiment Station, Gyeongsangbuk-Do, Korea. All the other ingredients like Saccharina japonica powder, anchovy powder, shiitake (Lentinus edodes) powder, tomato (Lycopersicum esculentum Mill) puree, parched soybean (Glycine max L.) powder, hot pepper (Capsicum annuum L.) seed, Chinese radish (Raphanus sativus L.), root of Chinese bellflower (Platycodon granidiflorum A, DC.), lotus root (Nelumbinis rhzoma), sesame powder, roasted salt, grain syrup, black sugar, soy sauce and water were purchased from local markets in Korea.

\section{Chemicals and reagents}

Falin-Ciocalteu reagent, gallic acid, 1,1-Diphenyl-2pricrylhydrazyl (DPPH), pyrogallol, 2-deoxyribose, thiobarbituric acid (TBA), trichloroacetic acid (TCA), ethylenediaminetetraacetic acid (EDTA) and phosphate buffer were purchased from Sigma Chemical co. (St. Louis, Mo, USA). Iron (II) sulfate heptahydrate $\left(\mathrm{FeSO}_{4} \cdot 7 \mathrm{H}_{2} \mathrm{O}\right)$ was purchased from Acro Orgamics (NJ, USA). Anhydrous sodium carbonate was purchased from J. T. Baker (NJ, USA) Ethanol and hydrogen peroxide were purchased from Merk (Darmstadt, Germany). All reagents used in the study were of analytical grade.

\section{Preparation of seasoning samples}

Hot peppers were harvested at the commercial maturity stage and transported to the lab within $2 \mathrm{~h}$ of harvest. The peppers were surface washed with tap water, kept for oven drying $\left(60^{\circ} \mathrm{C}, 8 \mathrm{~h}\right)$, seeds were separated from the fruits manually, and ground into powder (60 mesh) using a mixer (HMF 3450S, Hanil Co., Seoul, Korea). The hot pepper seed powder was stored at $4^{\circ} \mathrm{C}$ and used within $3 \mathrm{~d}$ for making seasonings.

The formula of ingredients used for the preparation of hot pepper seed seasonings in the present study are given in Table 1. Hot pepper seed powder and other ingredients (Table 1) were mixed thoroughly and simultaneously heated in a pan over hot plate (Prestige Euro ER-822W, Sunny Tech Ltd., Korea) for $45 \mathrm{~min}$. After heating for $45 \mathrm{~min}$, the samples were allowed to cool at room temperature and subjected to freeze dry. The freeze-dried mixture was milled (Speed Rotor Mill, KT-02A, Fukuoka, Japan) into powder and passed through a 100-mesh sieve. The strained samples were packed into airtight sample bottles and stored in refrigerator until analysis.

Table 1. Formula of recipe of seasoning prepared by adding different proportion of hot pepper seed powder (\%)

\begin{tabular}{lcccc}
\hline \multirow{2}{*}{ Ingredient } & \multicolumn{3}{c}{ Sample } \\
\cline { 2 - 5 } & NSP-0 & NSP-5 & NSP-10 & NSP-15 \\
\hline Saccharina japonica powder & 3.1 & 3.0 & 2.9 & 2.7 \\
Anchovy powder & 2.3 & 2.3 & 2.2 & 2.0 \\
Oak mushroom powder & 3.2 & 3.0 & 2.8 & 2.7 \\
Tomato puree & 1.5 & 1.5 & 1.4 & 1.3 \\
Parched soybean powder & 1.5 & 1.5 & 1.4 & 1.3 \\
Sesame powder & 1.3 & 1.0 & 1.0 & 0.9 \\
Hot pepper seed powders & 0 & 5.0 & 10 & 15 \\
Chinese radish & 1.5 & 1.5 & 1.4 & 1.3 \\
Doraji (root of Chinnese bellflower) & 0.2 & 0.1 & 0.1 & 0.1 \\
Roasted salt & 3.1 & 3.0 & 2.8 & 2.7 \\
Grain syrup & 8.7 & 7.3 & 6.9 & 6.5 \\
Black sugar & 1.7 & 1.5 & 1.4 & 1.3
\end{tabular}




$\begin{array}{lllll}\text { Soy sauce } & 46.7 & 44.1 & 40.5 & 37.0 \\ \text { Water } & 25.0 & 25.0 & 25.0 & 25.0\end{array}$

- NSP-0, seasoning prepared without adding hot pepper seed powder; NSP-5, seasoning prepared by adding $5 \%$ hot pepper seed powder; NSP-10, seasoning prepared by adding 10\% hot pepper seed powder; NSP-15, seasoning prepared by adding $15 \%$ hot pepper seed powder.

\section{Color measurement}

$\mathrm{L}^{*}$ (lightness), a* (redness, + or greenness, - ), and $\mathrm{b}^{*}$ (yellowness, + or blueness, - ) values of pepper seed seasonings were measured using a Chroma Meter (CR-300, Minolta Corp., Japan). A Minolta calibration plate $\left(\mathrm{Y}_{\mathrm{CIE}}=94.5, \mathrm{X}_{\mathrm{CIE}}=0.3160, \mathrm{Y}_{\mathrm{CIE}}=\right.$ $0.330)$ and a Hunter Lab standard plate $\left(L^{*}=82.13\right.$, a $\left.=-5.24, \mathrm{~b}^{*}=-0.55\right)$ were used to standardize the instrument with D65 illuminant. Color was measured directly on three zones of the seasonings and the average was calculated (Son et al., 2013).

\section{DPPH radical scavenging activity}

The scavenging activity of the extract from seasonings was measured with DPPH radicals according to the method of Blois (1958) with some modifications. One gram of pepper seed seasonings was extracted with $10 \mathrm{~mL}$ of ethanol for $12 \mathrm{~h}$. The mixture was centrifuged (3000 rpm for $15 \mathrm{~min}$ ) and supernatant was filtered using $0.22 \mu \mathrm{M}$ membrane filter (Millipore, USA). DPPH solution was prepared at the concentration of $4 \times 10^{-4} \mathrm{M}$ in ethanol. A 0.1 $\mathrm{mL}$ aliquot of extract was mixed with $2.9 \mathrm{~mL}$ of DPPH solution and the mixture was incubated in the room temperature for $30 \mathrm{~min}$. After standing for 30 min, absorbance was recorded at $516 \mathrm{~nm}$ by UV-VIS spectrophotometer (Opron 3000 Hanson Tech. Co. Ltd., Seoul, Korea). The inhibitory percentage of the DPPH radical by the samples was calculated according to Shyu and Hwang (Shyu and Hwang, 2002) as:

$\%$ inhibition $=\left[\left(A_{0}-\left(A-A_{b}\right)\right) / A_{0}\right] \times 100$

where, $A_{0}$ is the absorbance of DPPH without sample (control), $A$ is the absorbance of sample and DPPH, and $A_{0}$ is the absorbance of sample without DPPH (blank).

\section{Determination of total phenolic content}

The same ethanolic extract that was used for the DPPH radical scavenging assay was also used for measuring total phenolic content. The amount of total phenolics (TPH) was determined using the FolinCiocalteu method (Zheng and Wang, 2001). Five milliliter of distilled water was put into a $10-\mathrm{mL}$ volumetric flask. A suitable volume of the seasoning extract was transferred into the volumetric flask. A 0.2-mL aliquot of Folin-Ciocalteu reagent was added into the flask and carefully mixed. After $3 \mathrm{~min}, 0.4$ $\mathrm{mL}$ of $2 \% \quad \mathrm{Na}_{2} \mathrm{CO}_{3}$ solution was added, carefully mixed and made up to the mark with distilled water. After $1 \mathrm{~h}$ of reaction in the dark, the absorbance was measured at $725 \mathrm{~nm}$ using a spectrophotometer (Hewlett-Packard 8452A diode-array). A calibration curve using gallic acid (GA) was prepared and the results were expressed as mg GAE.g ${ }^{-1}$ (milligram gallic acid equivalent per gram) sample.

\section{Determination of free amino acid content}

Amino acid contents were analyzed following the procedure of Je et al. (2005) with some modifications. One gram of sample powder was hydrolyzed with 6 $\mathrm{N} \mathrm{HCl}(10 \mathrm{~mL})$ in a sealed-vacuum ampoule at $110{ }^{\circ} \mathrm{C}$ for $24 \mathrm{~h}$. The $\mathrm{HCl}$ was removed from the hydrolyzed sample on a rotary evaporator, brought to a known volume $(5 \mathrm{~mL})$ with $0.2 \mathrm{M}$ sodium citrate buffer ( $\mathrm{pH}$ 2.2). The sample was passed through a C18 Sep Pak (Waters Co. Milford, USA) cartridge and filtered through a $0.22 \mu \mathrm{M}$ membrane filter (Millipore, USA). Amino acids were determined on an automatic amino acid analyzer (Biochrom-20, Pharacia, Biotech Co., Sweden).

\section{Statistical analysis}

Data were subjected to analysis of variance (ANOVA) using Statistix version 8.0 (Analytical Software, AZ, USA). Differences between means at $\mathrm{p}<0.05$ were analyzed using the Tukey test.

\section{Results \\ Color of seasoning}

Significant variation in color value was observed among the seasoning samples prepared by adding hot pepper seeds (Table 2). The seasonings showed a significant increment in lightness, redness, and yellowness values with the increased amount of pepper seed powder. Increase in proportion of the pepper seed powder from 0 to $15 \%$ substantially increased lightness (35.12-60.17), redness (1.719.11), and yellowness (15.33-30.17). 
Table 2. Hunters color values of seasoning prepared by adding different hot pepper seed powders

\begin{tabular}{lcccc}
\hline \multirow{2}{*}{ Color value } & \multicolumn{3}{c}{ Sample } \\
\cline { 2 - 5 } & NSP-0 & NSP-5 & NSP-10 & NSP-15 \\
\hline L (Lightness) & $35.12 \pm 1.33^{\mathrm{d}}$ & $41.12 \pm 1.61^{\mathrm{c}}$ & $55.50 \pm 1.77^{\mathrm{b}}$ & $60.17 \pm 1.00^{\mathrm{a}}$ \\
a (Redness) & $1.71 \pm 0.31^{\mathrm{c}}$ & $5.31 \pm 1.18^{\mathrm{b}}$ & $9.00 \pm 0.51^{\mathrm{a}}$ & $9.11 \pm 0.81^{\mathrm{a}}$ \\
$\mathrm{b}$ (Yellowness) & $15.33 \pm 1.33^{\mathrm{d}}$ & $20.13 \pm 2.3^{\mathrm{c}}$ & $27.51 \pm 1.31^{\mathrm{b}}$ & $30.17 \pm 0.98^{\mathrm{a}}$
\end{tabular}

NSP-0, seasoning prepared without adding hot pepper seed powder; NSP-5, seasoning prepared by adding 5\% hot pepper seed powder; NSP-10, seasoning prepared by adding 10\% hot pepper seed powder; NSP-15, seasoning prepared by adding $15 \%$ hot pepper seed powder.

L: lightness (100, white ; 0, black), a: redness (-, green; +, red), b: yellowness (-, blue; +, yellow).

Values are mean \pm standard deviation of triplicate experiments.

The values followed by the different superscripts in the same row are significantly different, according to Tukey test $(\mathrm{p}<0.05)$.

\section{Scavenging activities and total phenolic contents of seasoning}

Free radical scavenging potential and antioxidant potential of the seasonings were determined by analyzing DPPH and total phenolic content (Table 3). Addition of hot pepper seed powder to the seasonings significantly enhanced the DPPH radical scavenging activities from $66.317 \%$ in control sample to $75.21 \%$ in the seasoning sample with $15 \%$ seed powder. Similarly, total phenolic content (200.1-244.2 mg GAE. ${ }^{-1}$ sample) was also significantly high in the seasonings containing hot pepper seed powder as compared to control sample (139.2 mg GAE.g ${ }^{-1}$ sample).

Table 3. Scavenging activity and total phenolic contents of seasoning prepared by adding different pepper seed powders

\begin{tabular}{lcccc}
\hline Sample & NSP-0 & NSP-5 & NSP-10 & NSP-15 \\
\hline DPPH (\% Inhibition) & $66.31 \pm 0.91^{\mathrm{d}}$ & $69.21 \pm 0.21^{\mathrm{c}}$ & $71.11 \pm 0.17^{\mathrm{b}}$ & $75.21 \pm 0.19^{\mathrm{a}}$ \\
Total phenolics & $139.2 \pm 1.9^{\mathrm{c}}$ & $200.1 \pm 2.1^{\mathrm{b}}$ & $241.6 \pm 2.7^{\mathrm{a}}$ & $244.2 \pm 3.9^{\mathrm{a}}$ \\
(mg GAE/g sample) & & &
\end{tabular}

-Quoted values are mean \pm standard deviation of duplicate experiments.

GAE: gallic acid equivalent.

DPPH: DPPH free radical scavenging activity.

NSP-0, seasoning prepared without adding hot pepper seed powder; NSP-5, seasoning prepared by adding 5\% hot pepper seed powder; NSP-10, seasoning prepared by adding $10 \%$ hot pepper seed powder; NSP-15, seasoning prepared by adding $15 \%$ hot pepper seed powder.

The values followed by the different superscripts in the same row are significantly different, according to Tukey test $(\mathrm{p}<0.05)$.

\section{Total amino acid content of seasoning}

Addition of hot pepper seed powder to the seasoning caused some of the amino acids to be increased while others (Table 4). Among the amino acids analyzed, glutamic acid (7012.77-7688.31 $\mu \mathrm{g} . \mathrm{mL}^{-1}$ sample), which was increased with the addition of pepper seed powder, was the most abundantly found. Others like serine, aspartic acid, valine, leucine, phenylalanine, proline, and isoleucine, were also abundantly found in the seasonings. Amino acids like phospho-serine, taurine, phospho ethanol amine, $\alpha$-aminoadipic acid, citrulline, $\alpha$-amino-n-butyric acid, cystine, cystathionine, hydroxylysine, ornithine, histidine, anserine, carnosine, arginine and hydroxy proline were not detected. 
Table 4. Amino acids content ( $\mu \mathrm{g} \cdot \mathrm{mL}^{-1}$ of sample) in seasonings prepared by adding different pepper seed powders

\begin{tabular}{|c|c|c|c|c|}
\hline \multirow{2}{*}{ Amino acid } & \multicolumn{4}{|c|}{ Sample } \\
\hline & NSP-0 & NSP-5 & NSP-10 & NSP-15 \\
\hline L-Aspartic acid & 3721.31 & 2711.31 & 2902.25 & 2812.31 \\
\hline L-Threonine & 1521.00 & 1112.21 & 1070.01 & 998.31 \\
\hline L-Serine & 1921.31 & 1032.00 & 1399.73 & 1300.66 \\
\hline L-Glutamic acid & 6631.21 & 7012.77 & 7597.36 & 7688.31 \\
\hline L-Sarcosine & 16.33 & 19.21 & 20.31 & 21.39 \\
\hline Glycine & 1621.12 & 883.21 & 886.75 & 866.71 \\
\hline L-Alanine & 2322.19 & 2521.00 & 2754.37 & 2933.71 \\
\hline L-Valine & 2121.12 & 2009.71 & 1692.43 & 1566.71 \\
\hline L-Methionine & 361.33 & 488.91 & 494.06 & 483.71 \\
\hline L-Isoleucine & 2212.66 & 1721.66 & 1698.97 & 1598.77 \\
\hline L-Leucine & 3002.54 & 2002.66 & 2378.51 & 2566.31 \\
\hline L-Tyrosine & 921.31 & 200.00 & 212.54 & 231.44 \\
\hline L-Phenylalanine & 2011.37 & 1066.31 & 1299.14 & 1361.21 \\
\hline$\beta$-Alanine & 371.66 & 213.77 & 448.57 & 447.26 \\
\hline $\mathrm{D}, \mathrm{L}-\beta$-Aminoisobutyric acid & 366.72 & 392.31 & 496.12 & 487.31 \\
\hline$\gamma$-Amino-n-butyric acid & 355.12 & 512.77 & 633.84 & 662.31 \\
\hline Ethanolamine & 132.37 & 66.77 & 99.56 & 89.31 \\
\hline Ammonia & 721.33 & 381.33 & 423.12 & 4721.00 \\
\hline L-Lysine & 2131.77 & 667.27 & 893.21 & 809.21 \\
\hline 1-Methyl-L-histidine & 1371.66 & 1521.33 & 1651.94 & 1777.37 \\
\hline 3-Methly-L-histidine & 71.77 & 65.31 & 67.06 & 63.21 \\
\hline Proline & 3100.29 & 923.66 & 1318.23 & 1721.22 \\
\hline Total free amino acid & 37007.49 & 27525.48 & 30438.08 & 35207.81 \\
\hline
\end{tabular}

Values are the means of duplicate experiments.

NSP-0, seasoning prepared without adding hot pepper seed powder; NSP-5, seasoning prepared by adding 5\% hot pepper seed powder; NSP-10, seasoning prepared by adding 10\% hot pepper seed powder; NSP-15, seasoning prepared by adding $15 \%$ hot pepper seed powder.

\section{Discussion}

The change in color expression demonstrated that addition of higher concentration of pepper seed powder would promote development of darker color of the seasonings. The darker color of seasonings at higher concentration of pepper seed powder might be because of color of pepper seeds itself and chemical reactions with other ingredients. Natural colorant areas like anthocyanins, betalains, chlorophylls, carotenoids, flavonoids, monascus, hemes, quinones, biliproteins, safflower, turmeric may be found as such and a variety of hues can be obtained ranging from green through yellow, orange, red, blue, and violet, depending on the source of colorant (Francis and Markakis, 1989). Color is one of the key factors in seasonings as they add different hues of colors to the foods.
Free radicals were highly reactive species and capable of damaging biologically relevant molecules such as DNA, proteins, carbohydrates, and lipids (Young and Woodside, 2001). Alteration of lipids, proteins, and DNA by free radicals might cause a number of human diseases (Lobo et al., 2010). However, the detrimental effects of free radicals could be corrected by the application of external source of antioxidants. Synthetic antioxidants like butylated hydroxytoluene and butylated hydroxyanisole had been reported to be dangerous for human health (Lobo et al., 2010). Pepper seed berries were rich in antioxidants (Jeon et al., 2012; Kedage et al., 2007) including melatonin (Vitalini et al., 2013), a novel antioxidant. Thus addition of pepper seed powder could increase the antioxidant potential of seasonings. 
Amino acids are the building blocks of proteins (Ekeanyanwu, 2013) that play an important roles in biochemical, biophysical, and physiological functions. Insufficient supply of proteins leads to different health disorders like weakness, anaemia, protein energy malnutrition (kwashiorkor and marasmus), delayed wound and fracture healing and also decreased resistance to infections.

Glutamic acid, glycine, alanine, proline, and aspartic acid were recognized as being important in the taste and their presence in the seasoning with pepper seed powder will enhance the properties of the seasoning (Choi et al., 1996). The results of the present study showed that contents of amino acids aspartic acid, proline, alanine, cysteine, valine, methionine, isoleucine, leucine, and lysine could be increased in the seasonings with the addition of pepper seed concentration extract.

In conclusion, addition of hot pepper seed powder to the seasonings enhanced the color values and antioxidant potentials. Seasonings prepared by adding different concentrations of pepper seed powder could be used as good sources of antioxidants in the human diet. Although some of the amino acid contents were found to be reduced while others were increased, results of this study suggested that addition of hot pepper seed powder to the seasonings could impart better physicochemical properties as well as enhance the antioxidant potential.

\section{Conflict of Interest}

The authors declare no conflict of interest.

\section{References}

1. Aggarwal BB, Ahmad N, Mukhtar H. 2002. Spices as potent antioxidants with therapeutic potential. In E. Cadenas and $\mathrm{L}$. Packer, eds. Handbook of Antioxidants. CRC Press, Los Angeles, USA.

2. Blois MS. 1958. Antioxidant determinations by the use of a stable free radical. Nature. 181: 1199-1200. http://dx.doi.org/10.1038/1811199a0

3. Chi SP, Wu YC. 2007. Spices and seasonings. In F. Toldrá, ed. Handbook of Fermented Meat and Poultry. Blackwell Publishing, Iowa, USA. 87p.

4. Choi YJ, Kim IS, Lee KW, Kim GB, Lee NG, Cho YJ. 1996 Available components of cooking drips, dark muscle, head and raw viscera from skipjack. Korean Journal of Fisheries and Aquatic Sciences. 29: 701-708.

5. Ekeanyanwu RC. 2013. Evaluation of the crude protein and amino acid composition of Nigerian Monodora myristica (Ehuru). Pakistan Journal of Nutrition. 12: 219-223. http://dx.doi.org/10.3923/pjn.2013.219.223

6. Ernst E, Pittler MH. 2000. Efficacy of ginger for nausea and vomiting: a systematic review of randomized clinical trials. British Journal of Anaesthesia. 84: 367-371. http://dx.doi.org/10.1093/oxfordjournals.bja.a013442

7. Francis FJ, Markakis PC. 1989. Food colorants: Anthocyanins. Critical Reviews in Food Science and Nutrition. 28: 273-314. http://dx.doi.org/10.1080/10408398909527503

8. Je JY, Park PJ, Jung WK, Kim SK. 2005. Amino acid changes in fermented oyster (Crassostrea gigas) sauce with different fermentation periods. Food Chemistry. 91: 15-18. http://dx.doi.org/10.1016/j.foodchem.2004.05.061
9. Jeon G, Choi Y, Lee SM, Kim Y, Jeong HS, Lee J. 2010. Anti-obesity activity of methanol extract from hot pepper (Capsicum апnиит L.) seeds in 3T3-L1 adipocyte. Food Science and Biotechnology. 19: 1123-1127. http://dx.doi.org/10.1007/s10068-010-0160-5

10. Jeon G, Choi Y, LEE SM, Kim Y, Oh M, JEONG HS, Lee J. 2012. Antioxidant and antiproliferative properties of hot pepper (Capsicum annuum L.) seeds. Journal of Food Biochemistry. 36: 595-603. http://dx.doi.org/10.1111/j.17454514.2011.00571.x

11. Kedage V, Tilak J, Dixit G, Devasagayam T, Mhatre M 2007. A study of antioxidant properties of some varieties of pepper seeds (Vitis vinifera L.). Critical Reviews in Food Science and Nutrition. 47: 175-185. http://dx.doi.org/10.1080/10408390600634598

12. Lobo V, Patil A, Phatak A, Chandra N. 2010. Free radicals, antioxidants and functional foods: Impact on human health Pharmacognosy Reviews. 4: 118-126. http://dx.doi.org/10.4103/0973-7847.70902

13. Naidu KA, Thippeswamy NB. 2002. Inhibition of human low density lipoprotein oxidation by active principles from spices. Molecular and Cellular Biochemistry. 229: 19-23. http://dx.doi.org/10.1023/a:1017930708099

14. Paur I, Carlsen MH, Halvorsen BL, Blomhoff R. 2011. Antioxidants in herbs and spices: Roles in oxidative stress and redox signaling. In I. F.F. Benzie, and S. Wachtel-Galor, eds. Herbal Medicine: Biomolecular and Clinical Aspects. CRS Press, Boca Raton, USA.

15. Ruggiero A, Vitalini S, Burlini N, Bernasconi S, Iriti M. 2013. Phytosterols in grapes and wine, and effects of agrochemicals on their levels. Food Chemistry. 141: 34733479. http://dx.doi.org/10.1016/j.foodchem.2013.05.153

16. Shan B, Cai YZ, Sun M, Corke H. 2005. Antioxidant capacity of 26 spice extracts and characterization of their phenolic constituents. Journal of Agricultural and Food Chemistry. $\quad 53: \quad 7749-7759$ http://dx.doi.org/10.1021/jf051513y

17. Shyu YS, Hwang LS. 2002. Antioxidant activity of the crude extract of crude extract of lignan glycosides from unroasted Burma black sesame meal. Food Research International. 35: 357-365. http://dx.doi.org/10.1016/s0963-9969(01)00130-2

18. Son JH, Kim ID, Kim MO, Gaveh EA, Shin DH. 2013 Quality characteristics of rice inoculated with Inonotus obliquus mycelia and incubated under different cultivating conditions. African Journal of Biotechnology. 12: 5131-5139. http://dx.doi.org/10.5897/ajb12.2387

19. Srinivasan K, Sambaiah K, Chandrasekhara N. 2004. Spices as beneficial hypolipidaemic food adjuncts: A review. Food Reviews $\quad$ International. 20: $187-220$ http://dx.doi.org/10.1081/fri-120037160

20. Vitalini S, Gardana C, Simonetti P, Fico G, Iriti M. 2013. Melatonin, melatonin isomers and stilbenes in Italian traditional pepper seed products and their antiradical capacity. Journal of Pineal Research. 54: 322-333. http://dx.doi.org/10.1111/jpi.12028

21. Young IS, Woodside JV. 2001. Antioxidants in health and disease. Journal of Clinical Pathology. 54: 176-186. http://dx.doi.org/10.1136/jcp.54.3.176

22. Zheng W, Wang SY. 2001. Antioxidant activity and phenolic compounds in selected herbs. Journal of Agricultural and Food Chemistry. 49: 5165-5170 http://dx.doi.org/10.1021/jf010697n

23. Zou Y, Ma K, Tian M. 2015. Chemical composition and nutritive value of hot pepper seed (Capsicum аппиит) grown in northeast region of China. Food Science and Technology. (Campinas). 35: 659-663. http://dx.doi.org/10.1590/1678$457 x .6803$ 